exaggerated sphere of its usefulness; nor do I imply any disparagement of the ordinary methods in respect of which contactillumination may serve as a useful adjunct on particular occasions. Such occasions are the detection of fine corneal opacities and of early keratitis punctata against a light background, or the detection of the surface haze of slightly raised tension, or the investigation of small abnormalities in the anterior chamber and lens.

I am indebted to the Surgeons of Moorfields Hospital for their courtesy in permitting me to examine and to quote from the records of their cases.

I have frequently referred both to Mr. Treacher Collins and to Mr. Herbert Parsons for their opinions and advice; the readiness with which they have accorded these is a kindness for which I am very grateful.

\title{
THE OCULAR MENACE OF WOOD ALCOHOL POISONING*
}

BY

\section{DR. S. LEWIS ZIEGLER}

PHILADELPHIA.

THE adoption of the National Prohibition Amendment in the United States, and the possible advent of similar restrictions in Great Britain, make the ocular complications of wood alcohol poisoning a live topic for discussion. The more we restrict the use of ethyl alcohol the greater is the temptation to substitute methyl alcohol, and so long as methyl alcohol remains the most deadly poison of daily commerce so long will human eyesight, if not life itself, be menaced by ignorant, careless or criminal handling of this toxic product. As ophthalmologists we have a double duty to perform:-(1) to make an intensive study of the toxic effects of methyl alcohol on the delicate ocular tissues, and (2) to establish a propaganda in "preventive medicine" that will protect possible victims, whether guilty or innocent.

Three fateful factors have increased the dangers of wood alcohol: (1) its refinement from a nauseous, vile smelling compound to one as clear and palatable as ethyl alcohol, (2) its fatal cheapness, which has naturally resulted from the increased output and the improved methods of manufacture, and (3) its unusual solvent power, which has so greatly encouraged its use in the Arts.

In America we have (1) ethyl alcohol, which is either absolute (99 per cent.) or rectified (90 per cent.) ; (2) methyl alcohol, which

${ }^{*}$ Read at the Oxiford Ophthalmological Congress, July 15, 1920. 
may be either the commercially impure liquid or the purified product, and (3) denatured alcohol, which was formerly composed of 10 parts of methyl alcohol and 1/2 part of pyridin bases, added to 100 parts of ethyl alcohol, but since December, 1919, this formula has been modified by a reduction of the methyl alcohol from 10 per cent. to 2 per cent. There is a well founded suspicion that in order to evade the Prohibition Act unscrupulous chemists are submitting this denatured alcohol to fractional distillation so as to remove the benzine and wood alcohol and thus secure an impure ethyl alcohol which can be sold for drinking purposes.

In the United Kingdom this product is better regulated, and, therefore, the cases of blindness have been fewer, although it is quite possible that many cases have escaped detection and reporting. According to the "Extra Pharmacopoeia" of Martindale and Westcott for 1920, you have (1) ethyl alcohol of 99 per cent. and 90 per cent. strength ; (2) methyl alcohol, pure, which can only be retailed at increased cost subject to excise duty, and the impure or commercial variety which is 60 per cent. to 90 per cent. pure and is sold as wood naptha," its use being forbidden in medicines and beverages but permitted in liniments, e.g., aconite, belladonna, compound camphor and soap liniments; (3) methylated spirits, consisting of (a) mineralised alcohol, which is a denatured product containing wood naptha 10 per cent., mineral naptha $5 / 8$ per cent., methyl violet $q . s$. to colour, in each 100 parts of ethyl alcohol, used chiefly as a burning fluid; and (b) industrial alcohol, containing 5 per cent. of wood naptha, used mostly in varnishes. The "colour indicator" is a better warning to the eye than a poison label, but both should be used to designate pure methyl alcohol and wood naptha instead of the less dangerous mineralised alcohol. The use of wood alcohol in liniments and burning fluids should be legally prohibited.

In New York, the late Dr. Gruening, in 1910, showed that wood alcohol was a fairly constant ingredient in the cheaper wines, brandies and whiskies sold in the low resorts of the East Side, in proportions varying from 24 to 43 per cent. These large percentages proved most disastrous to the victims who drank these liquors. He urged frequent analyses and regulation under the restrictions of "The National Food and Drug Act" of 1906.

In Pennsylvania, Dr. Edward Martin, Commissioner of Health, under the State Act of July, 1919, requires all manufacturers of drugs and toilet preparations to file an affidavit that the alcoholic content is pure grain alcohol, and that no wood alcohol has been used in the preparation. This has proved to be a great step forward in effective restriction, but at first there was difficulty in controlling the jobbers in barbers' supplies and the small retailers of toilet articles. The prompt closing of several stores, and the 
confiscation of their adulterated goods, soon convinced the dealers that this law would be rigidly enforced.

\section{Commercial Sources of Supply}

The City Chemist of Philadelphia found methyl impurities in bay rum, lilac and violet waters, quinine and other hair tonics. Chemical analyses have also revealed its presence in Cologne spirits, spirits of lavender, Florida water, witch hazel, balsam of myrrh, paregoric, Jamaica ginger, vanilla extract, lemon extract and the essences of anise, peppermint, cinnamon and capsicum-better known as "hot drops." Well known perfumes, foreign wines, and patent medicines have also been found to be adulterated with it. In its pure state it is sold in bottles as Columbian spirits, Eagle spirits, Lion d'Or, Colonial spirits, Hastings spirits or acetone alcohol.

It has been used to fortify and preserve ginger ale, ginger beer, and bottled cider. I have seen one patient blinded by drinking a single bottle of fortified cider purchased at a country grocery store. Fourteen cases of blindness from drinking Jamaica ginger were recorded in Baltimore a few years ago. During prosecution for damages an official of the factory took a large draught to show its harmlessness, but secretly followed this with an emetic. Many Indians from our Reservations while on spree have been blinded by drinking lemon extract that was similarly adulterated. The case of sudden blindness with vomiting after drinking a single bottle of "Wincarnis Quinine Tonic" points more to methylic than to quinine toxemia, since the whole bottle contains only twelve grains of quinine, but this is dissolved in imported Spanish wine that could easily be adulterated at its source. The victim of this debauch might, however, have indulged in some other potation with methylic content.

It is the basis of all so-called "burning fluids" which are freely used in the chafing dish, to heat the vapour bath cabinet and to boil water. In rooms with poor ventilation the fumes are always dangerous.

Bathing the hands, face and head with these solutions has also been followed by toxic effects.

The "anti-freeze" mixtures, which have been sold so freely for use in the engines of motor vehicles are almost wholly composed of wood alcohol. These mixtures have often been stolen by garage employees and recklessly sold to unwary victims. It is easy to understand, therefore, what a terrific toll of sudden blindness and death followed the wood alcohol orgy in the United States during the first year of prohibition.

Many liniments and veterinary preparations have a large methylic content and may, therefore, prove dangerous. No legal restrictions have as yet been placed upon them. 
The largest manufacturer of wood alcohol in America has recently designated his product "Methanol," which will at least remove the temptation of alcoholic suggestion to the confirmed drinker. When the morale of the caretaker of an anatomical museum falls so low that he will drink the alcohol off the specimens under his charge, we can understand why the significance of the word wood in front of the word alcohol will not impress the toper's vision until after he has taken a lethal dose and blindness has ensued.

We cannot prevent the "confirmed alcoholic" who is ignorant, secretive or reckless from becoming an easy prey to its poisonous effects, but we can legally prevent the ignorant or unscrupulous manufacturer from substituting methyl for grain alcohol in his pharmaceutical products, flavouring extracts and toilet preparations. Furthermore,we can by pitiless publicity, teach the public the dangers they face in drinking or otherwise using compounds containing this poison.

No restrictions have been placed on the use of wood alcohol in the Arts, and no warning has been given as to its dangers. The official reports of Great Britain show that during the year 1914 over $1,100,000$ gallons were used in varnishes. We may reasonably infer that some ocular injury followed the use of such an enormous output.

As to its relative cost, the wholesaler in America buys it by the barrel at about one-eighth the price of grain alcohol. Denatured alcohol is equally cheap, but it does not cut varnish as well, and the disagreeable odour and taste prevent its use in toilet preparations and pharmaceuticals. In Great Britain, most fortunately for you, the relative wholesale prices are reversed, because wood alcohol is scarce and consequently dear; hence, pure methyl alcohol costs as much as, or even more than, ethyl alcohol. The temptation to substitute it for ethyl alcohol is, therefore, greatly lessened. You have, moreover, the distinct advantage of better and more systematic inspection and regulation which prevents the pollution of your products by careless or criminal profiteers. The one great danger to you is the possible importation from other countries of wines, whiskies, toilet articles and patent medicines that have been adulterated with wood alcohol at their place of manufacture.

The mere existence of commercial compounds containing wood alcohol constitutes a menace to the eyes and lives of the community, and their manufacture and sale should be strictly prohibited or regulated by law, punishable by fine and imprisonment. If their use is permitted, the contents should be coloured with methyl violet and a poison label affixed to each container stating that the use of this preparation by "drinking, breathing or rubbing on skin may cause blindness or death." Instructions should also be issued to the trades affected, calling attention to the dangers of using wood 
alcohol to varnish tanks, closets or rooms where the air is confined, requiring proper ventilation and ordering employees to seek the air at stated intervals of two hours. These public duties would naturally fall to the existing Department of Health, but it is our plain duty to see that all information as to its manifest danger to vision is properly disseminated to the public. A special revenue tax should be imposed and a record of "poison sales" required for both wholesalers and retailers. The tax on denatured alcohol, should be reduced or equalized so that it can be sold cheaper than methyl alcohol thus removing the temptation to substitute because of cheapness. In addition to this the law should require that every case of wood alcohol poisoning should be reported and the source of supply revealed. I believe, however, as previously stated, that the only safe plan is to limit the manufacture of wood alcohol and regulate its sale, since it constitutes the most deadly poison used in daily commerce. Manufacturers who use this product in their business should be the first to seek a substitute and join us in this crusade to abolish its use, since they would be subjected to compensation damages if their employees were injured by its use.

\section{Tests for Wood Alcohol}

Mulliken and Scudder's Test.-In order to determine quickly the presence or absence of wood alcohol, the test of Mulliken and Scudder has often been employed but has not always proved sufficiently dependable. Nevertheless, it is a test that a travelling liquor inspector can quickly utilize. It depends on rapid oxidation by plunging a red-hot copper spiral wire into the suspected liquid, or into a distillate made from the same. Formaldehyde is thus formed and its pungent odour can be recognized by the stinging sensation it produces in the upper part of the nose. This test is only useful where the methylic strength is over ten per cent.

Robinson's Test.-A more practical method, which can be easily applied, has recently been devised by the Chemist to the Department of Public Health of Philadelphia, Dr. William C. Robinson. He converts the wood alcohol by oxidation through potassium permanganate into formaldehyde, then adds it to acidulated milk and gently heats until a pink colour develops. This test is so delicate that $1 / 100$ of one per cent. of methyl alcohol will be revealed.

\section{Quantitative Test}

1. Take 100 cc. of the suspected methylic liquid and add sodium carbonate until it becomes alkaline.

2. Dilute this with an equal volume of water.

3. Then distil the solution.

4. Cool $100 \mathrm{cc}$. of the distillate to $60^{\circ} \mathrm{F}$. and take the Sp. Gr. 
5. Compare Sp. Gr. with tables to estimate percentage of alcohol by weight and volume.

6. Pour distillate into a Zeiss Immersion Refractometer and compare scale reading and reference table to ascertain whether pure ethyl alcohol, pure methyl alcohol, or a mixture is present.

7. If both are present, obtain percentages of each by applying an empiric formula (See fourth edition of Leach's "Food Inspection and Analysis," p. 782).

\section{Qualitative Tèst}

8. Redistil the remaining $100 \mathrm{cc}$. of distillate (para. 4 above.)

9. Take the first $10 \mathrm{cc}$. coming over and add $3 \mathrm{cc}$. of 1 per cent. solution of potassium permanganate.

10. Gently heat to $110^{\circ} \mathrm{F}$. and constantly agitate the vessel until the odour of ethyl aldehyde is perceptible.

11. If the solution decolourizes add more permanganate solution, $1 \mathrm{cc}$. at a time, until pink colour is restored.

12. Add a few drops of commercial muriatic acid to precipitate the excess of permanganate (as brown manganese hydroxide) and filter.

13. Pour the colourless filtrate into a porcelain casserole and add $10 \mathrm{cc}$. each of water, fresh milk and muriatic acid.

14. Heat mixture to the boiling point with constant agitation until a bright permanent pink develops, which will occur if only $1 / 100$ of one per cent. of wood alcohol is present in the suspected liquid.

For an emergency inspection we can modify the quantitative test outlined above by omitting the distillation. The suspected methylic liquid is thus poured directly into the hygrometer and $Z$ eiss refractometer, and readings of specific gravity and percentages compared with reference table and empiric formula (as in Nos. 5, 6 and 7). This will roughly show the relative amounts of ethyl and methyl alcohol present.

\section{Port of Entry through the Mouth, Nose and Skin}

We should always bear in mind that wood alcohol may develop its lethal action through three different avenues of entrance into the system; (1) by ingestion, (2) by inhalation, and (3) by cutaneous absorption.

1. Ingestion is usually the most common method of poisoning. If taken pure, a single teaspoonful has been known to cause blindness, and an ounce to cause death. As different individuals seem to be variously affected, there may be an idiosyncrasy present that increases immunity. Thus, if three persons indulge in a wood alcohol spree, newspaper reports will usually state that "two died 
and one went blind." Increase of tolerance is also acquired by long exposure to the poison, as in the case of painters.

The acute toxic symptoms that usually follow ingestion are headache, dizziness, nausea, vomiting, abdominal pain, chilliness, leaky skin, cardiac weakness, slow pulse, sighing respiration, marked physical prostration, weakness of the extremities, delirium, convulsions, stupor, and finally death. Blindness is usually noticed by the patient on the second day, when the stupor begins to wear off. Many observers have noted that early and persistent vomiting has been followed by clearing vision. In like manner prompt relief of the toxemia may avert blindness. On the other hand, blindness may ensue where acute systemic symptoms have been wholly absent. The symptoms from a single large dose, and those from repeated small doses, may show considerable variation.

2. Inhalation of the fumes of wood alcohol may be followed by blindness. This method of poisoning is more chronic and insidious, and has often been denied, but recorded histories verify the fact.

Loewy and von der Heide, by animal experimentation, determined that 0.2 per cent. of wood alcohol in the inspired air will cause body saturation if continued long enough. They observed, further, that the fat absorbed less of the poisonous fumes than the lean.

Buller and Wood have recorded eleven cases of poisoning by inhalation, Gruening two, Tyson three, and de Schweinitz one. I have seen two cases of poisoning by inhalation. One patient (Case III) inhaled the fumes for only one hour a day in a chinacement factory. The second patient (Case VI), inhaled the fumes for three days while varnishing the small engine room of a submarine.

The majority of these cases occur from occupational exposure to the fumes. The painter uses it as a cleansing fluid or as a cheap diluent to "cut" his shellac in order to varnish the interior of large beer vats, closets or closed rooms. Two of Tyson's cases shellaced lead pencils in a fairly large room, but finally succumbed to the slow poisoning. The hatter mixes it with shellac to stiffen his nap or straw blanks; the dyer of feathers uses it to dilute his colours; the maker of shoe polish adds it to his paste; the brass finisher uses it in his lacquer, and the maker of rubber tyres mixes his mass with it. If ventilation is very free the danger will be lessened, but open-air exercise at frequent intervals should be required for every such employee. Sooner or later some ocular injury becomes manifest in spite of every precaution.

3. Cutaneous absorption has also been denied, but there are many cases of recorded blindness. These have arisen chiefly from the daily application of bay rum, toilet waters and liniments. Some were caused by the washing of the face, head and hands in pure 
methyl alcohol. Even Turkish bath rubbers are not exempt from toxic absorption, although they only apply it occasionally. Buller and Wood have recorded several cases, and E. V. L. Brown, in discussing Friedenberg's paper on "Wood Alcohol Amaurosis" (Trans. Amer. Ophthal. Soc., 1910) relates a typical case of a painter who spilled a gallon of wood alcohol down his leg, soaking his clothes, and filling his shoe. $\mathrm{He}$ carelessly allowed this to dry on his skin. Toxemia and blindness resulted in a few days.

\section{Symptomatology}

The ocular symptoms are not pathognomonic, but vary within certain limitations. As a rule, vision is seriously impaired. Blindness may be early, sudden and complete. At the end of a month there may be marked recovery, which either remains permanent or is followed by gradual failure and ultimate blindness. This history of variable vision associated with gastro-intestinal symptoms is typical enough to make us suspect wood alcohol as the causative factor. When there is chronic poisoning the visual loss is more insidious, and the diagnosis is more difficult.

The objective symptoms are a. sluggish, well-dilated pupil, which may or may not react to light or convergence, scleral congestion, deep pain on rotation of the globe, tenderness on finger pressure, and occasionally paresis of one or more of the extra-ocular muscles accompanied by diplopia. Sometimes the levator of the lid is involved and ptosis results.

The optic nerve-head shows many variations, but no characteristic appearance. The conditions most frequently recorded are (a) papillitis, (b) retro-bulbar neuritis, and (c) sudden sclerosis :-

(a) Pabillitis. The swelling of the papilla may reach 2D. The oedema may spread over the margins on to the retina. The edges may be dusky-red with dark, dilated veins and shrunken arteries. This papillitis generally subsides in from one to two weeks. It somewhat resembles influenzal papillitis, but the latter yields more readily to hot packs or other diaphoresis, and the vision recovers more quickly and completely. Associated symptoms of intracranial pressure must, of course, be eliminated in making a diagnosis.

(b) Retro-bulbar Neuritis. These cases are more insidious. They are often followed by a decided shrinkage of the nerve-head, sometimes in the form of a sector-like excavation, limited to a quarter or half of the disc, glistening white in appearance, or with bluish tint, revealing the lamina cribrosa in the excavation, but usually free from connective tissue deposit. Fridenberg believes this appearance to be characteristic of this lesion; de Schweinitz and E. V. L. Brown confirm this observation of sector atrophy of the papillo-macular bundle, but with certain modifications.

(c) Sudden Sclerosis may occur immediately after ingestion, and 
reveals chalky white pallor of the papilla, without the slightest appearance of shrinkage. I have seen several cases of this kind and they are equally typical.

(To be continued).

\section{ANNOTATIONS}

\section{- Mansion House Meeting on Hospital Finance}

Under the auspices of King Edward's Hospital Fund for London, a meeting of representatives of all the London Hospitals took place at the Mansion House on Wednesday, July 6, 1921, Lord Stuart of Wortley in the chair.

The object of the conference was to discuss the three schemes of "mass contributions" referred to by Lord Cave's Committee as dikely to provide the key to the problem of hospital finance, namely : (A) Organized weekly contributions of wage-earners on a large scale, but without any definite insurance system; (B) the Oxford scheme, under which the contributors pay $2 \mathrm{~d}$. per week, and are entitled to free treatment; whereas non-contributors are expected to pay; (C) the Sussex scheme, under which, in the modified form proposed for London, the contributor pays $5 \mathrm{~d}$. per week and the hospital gets about as much as under the "Oxford" scheme, the payment also providing the members with other facilities, such as private consultations, dental treatment, etc.

Lord Cave's Committee gave two years for the re-establishment of the finances of the hospitals, but that pre-supposed the acceptance of their recommendation of a Government emergency grant of $£ 1,000,000$ for the first year, and possibly less in the second, whereas the Government had only suggested $£ 500,000$ for the first year conditional on the hospitals taking for themselves all possible steps to get over their financial difficulty. In other words, adopting one of the above schemes in some form or other.

Most of the representatives of the hospitals present were strongly in favour of scheme "A," but the governing bodies of The London, St. Thomas's and The Royal Free had already committed themselves to the Sussex scheme before the meeting. It is obvious that such schemes as the "Oxford" or "Sussex" scheme would not be satisfactory for the ophthalmic hospitals of London. First, because the ophthalmic hospitals of London supply a far wider area than London itself ; secondly, because there could be no way of defining the areas from which contributions could be made to each individual hospital, and thirdly, that at any rate the "Sussex" 